on the use of animals together in circumstances in which there are practical and not merely grand philosophical questions to be decided. So why not build into a new system of regulation a device that has worked well in the regulation of genetic manipulation and of experimental procedures with human subjects - a committee at every important centre at which animals are used that would be empowered to sanction (or not to sanction) proposed uses of laboratory animals? Such a mechanism would be more than an exercise in public relations, for it could help to define if not to answer the philosophical questions that at present ensure that all legislations seems arbitrary to those most concerned. It need not impede the conduct of research nor rob the government of the political responsibility that it seems to cherish. And, if well run, such a system, while requiring of some scientists an extra committee meeting, could simplify and rationalize the present system of licensing.

\section{Away with Kondratiev}

L.ittle has been heard of the Centre for Technical Change since it was first set up by the Leverhulme Trust and a consortium of British research councils just over a year ago. The delay, a little at odds with the declared objectives of understanding what is wrong with the British economy, is forgivable in that, as always, the recruitment of staff for a purpose-built organization is necessarily slow. Some hint of which way the wind is blowing can, however, be gleaned from the paper delivered earlier this week to the Institute of Ceramics by the director of the centre, Sir Bruce Williams. His theme was the question of how to strike a balance between technical innovation, economic growth and leisure either enforced - as unemployment - or arranged as by means of education (which delays entry to the labour force), shorter working weeks or earlier retirement. His paper should be read in conjunction with a study, "Innovation and Efficiency' by Haustein, Maier and UhImann, now published in the institute's series of IIASA Reports $(3,309 ; 1981)$.

Both arguments start by distinguishing between product and process innovations - respectively the innovations that introduce new products to the market and those which result either in the improvement of existing products or more efficient ways of making them. Of necessity, product innovations increase jobs, and process innovations decrease them. Williams refers to the Kondratiev cycle, the forty-to-fifty year cycle in economic activity attributed by Schumpter to the coincidence of innovations of all kinds at certain periods of time. Haustein et al. have carried out a study of the decline of productivity in industrialized countries over the past thirty years (in both "planned" and capitalist economies, Japan included) and, concluding that there is indeed a cycle in the "efficiency" of the process of innovation, unremarkably suggest that the success of an innovation is determined by such considerations as market potential, the organization of the firm or organization concerned and "know-how", whatever that may be.

Williams, as might be expected, is more pragmatic. This may be a time of downturn in the Kondratiev cycle, and thus a time when the opportunity for jobs is also declining. But, with luck, there will eventually be an upturn. In the meantime, it might help if governments were to concentrate support for research and development on job-creating innovations. All this is sensible enough. But can either analysis be correct? Even the past few years have not been short on product innovations. The benefits of microelectronics have been widely touted, yet the benefits have not been quickly spread about because potential customers have not been able to afford them. Part of the trouble is that the manufacture of microelectronic equipment is labour intensive, which means that potential purchasers of, say, a home computer must also undertake to provide somebody else's food and drink. The same, so to speak, is even more true in telecommunications, where the cost of installation often far outweighs the cost of manufacture. It is also manifest that the growth of most economies in the past thirty years has been sustained by the improvement of agricultural productivity. So perhaps the way to avoid the Kondratiev cycle is to invest in process and not product innovation, contrary to expectation. Enabling the market to function is at least half the battle.

\section{Back to the Pleistocene}

Western Europe is plainly in for another bout of preoccupation with the building of a tunnel beneath the English Channel or La Manche, according to where you live. Observers of last week's meeting between the British Prime Minister, Mrs Margaret Thatcher, and the President of France, M. Francois Mitterrand, seem unaccountably to have been at a loss to understand their cordiality (yet both are well-mannered people) and their decision to resurrect once again this ancient technological project, so long in the tooth that it was first abandoned when the British took fright that Napoleon might march an invading army beneath the sea. Last week's agreement to carry out yet another feasibility study of the tunnel is, however, not at all surprising. The two politicians may differ in their politics but they share a common preoccupation with high and rising unemployment and the knowledge that its amelioration by the spending of domestic resources would entail that the printing presses would have to work harder than at present and that the consequences would be inflationary. Among megaprojects, however, the Channel Tunnel has the advantage that it might be possible to persuade the rest of the European Community to pay for a substantial part of the cost, on the grounds that it would assist the flow of trade within Europe as a whole. Yet whatever the European Community contributes, the chances are high that the immediate benefits would accrue in Britain and France. So much of the feasibility study will be among the moneybags of Brussels.

Even if the immediate objective is economic, however, it will be in the public interest, both in Britain and in France, that technical considerations should not be overlooked. Some attention should also be paid to the reasons why previous proposals have collapsed. In 1975, for example, the proposed rail tunnel between Britain and France foundered on the gloomy calculations by British Rail of the cost of providing a railhead in Kent and a terminus in central London. The correctness of the decision was reinforced by the widespread disbelief that the railways would be able to load special trains with vehicles at a rate of one cvery few minutes and by the no doubt cynical conviction that to give the British and French railways a monopoly of wheeled communication between the two countries would merely provide them with a permanent means of recovering the cost of uneconomic services elsewhere. The lesson is that if there is to be a direct link between Britain and France, it should not be exclusively a rail link.

With the passage of time since 1975 , other candidate proposals for a direct link have emerged. British Steel and other European steel-making concerns are understandably keen to build a bridge most of the way across, using sections of immersed-tube tunnel in the shipping lanes. Unfortunately, none of these plans takes full account of the suitability of the Channel (or of La Manche) as the site for a feasible megaproject - the fact that it is nowhere deeper than fifty metres, with an average depth of some thirty-five metres. In such circumstances, dam-building is by no means out of court. Indeed, with a little ingenuity, the civil engineers could arrange to provide not merely a means of walking from Britain to France but also of providing the whole of Europe with electricity. To the complaint that a dam would interfere with shipping there is the quite proper riposte that most of the ships are there only because the Channel (or La Manche) has taken the place of the late Pleistocene land-bridge. Industrial consortia wishing to pursue this option should consult the report of the competition to dam the Channel organized by Nature in $1968(220,1168)$. They should reflect that no harm will come from thinking big, for the new feasibility study, like its predecessors, is likely to conclude that building a link between Britain and France is no longer economically feasible even though it would have paid off handsomely if the decision had been taken at some earlier stage. 